\title{
Morphological and Colony Characterization of Durg Isolates of Entomopathogenic Fungi as a Biocontrol Agent against Tick infestation in Cattle
}

\author{
Jumade Pratibha*, S. Pal and P. K. Sanyal \\ Department of Parasitology, College of Veterinary Science and Animal Husbandry, \\ Anjora, Durg, C.G., India \\ *Corresponding author
}

\section{A B S T R A C T}

\section{Keywords}

Entomopathogenic, Fungi, Ticks,

Cultural, Hyphae, Conidia

Article Info

\section{Accepted:}

15 June 2021

Available Online:

10 July 2021
The study of cultural and morphological characters of six isolates of entomopathogenic fungi isolated from organic environment of Durg District of Chhattisgarh namely; Fusarium sp. strain FW24, Rhizopus oryzae, Metarhizium majus and Trichoderma harzianum as well as from naturally infected ticks namely; Aspergillus amstelodami and Fusarium beomiforme was conducted. The study of macroscopic cultural characters of Fusarium sp. strain FW24 and Rhizopus oryzae, Fusarium beomiforme showed abundant cottony luxuriant, fluffy, raised and suppressed mycelium, white colony colour whereas the reverse colony colour was light yellow to peach violet. Rhizopus oryzae showed blackish grey colony colour whereas the reverse colony colour was observed as reddish brown. Trichoderma harzianum isolates were observed as diffused, luxuriant and suppressed mycelium with green colony colour and yellowish brown reverse colony colour. Aspergillus amstelodami isolates were noted as thick luxuriant, suppressed and folded mycelium with yellowish green colony colour and brownish red reverse colony colour. The cultural appearances of Metarhizium majus was smooth, diffused, luxuriant and suppressed mycelium with green colony colour which were turned in olive green after maturation and yellowish brown reverse colony colour. The length of hyphae of all EPF varies from 200 to $400 \mathrm{um}$, macrocondia varies from 12-150 um x 3.2-18um in length $\mathrm{x}$ width. Size of microconidia ranges from 3.5-9um x 1.90-4.5um in length $\mathrm{x}$ width.

\section{Introduction}

Biological control is becoming an increasingly attractive approach and giving promising results to tick management because of increasing concerns about environmental safety and human health (Samish et al., 2004). Biological control of ticks using entomopathogenic fungus is proved to be most economical and safest method to overcome the risk of environmental pollution and acaricidal resistance. EPF are being used as myco- 
insecticides in horticulture, forestry and agriculture sector. An entomopathogenic fungus is a fungus that can act as a parasite of insects. This fungus kills or seriously disables their host by their insecticidal toxicity. As per the recent and existing research, the entomopathogenic fungi show minimal adverse effects on the animals and other nontarget organisms. They can be used in integrated pest management replacing the conventional chemical insecticides (Pell et al., 2001). Although entomopathogenic fungi have been widely used for the control of agricultural and forest pests but their application against animal pests is in rudimentary stage and meager references are available in India on mass applicability of this fungi for control of ticks. The present research work was planned to isolate the EPF from organic environment as well as from naturally infected ticks from Durg district of Chhattisgarh and their identification based on cultural and morphological characters.

\section{Materials and Methods}

Sixty soil samples were collected from crop roots of various cultivated agricultural fields in Durg district of Chhattisgarh to explore the isolates of entomopathogenic fungi. The isolation of fungi from soil samples were enumerated by using serial soil dilution and soil plate method.(Waksman,1922). The serially diluted soil samples at the concentration of $10^{2}$ dilution were cultivated on Potato Dextrose Agar medium by incubating at $29^{\circ} \mathrm{C}$ temperature and $75 \%$ relative humidity in BOD incubator until the full fungal growth was achieved. The ticks collected from body of animals were rinsed with distilled water and then treated with $1 \%$ Potassium Hypo Chloride solution for bacterial contamination. The surface sterilized ticks were infected with conidial suspension of fungal isolates. The fungal isolates causing the death of ticks and showing mycelium growth on their body surfaces were separated, subcultured to maintain the pure culture and were assumed as entomopathogenic fungi. The surface sterile ticks were also observed for natural fungal growth on their body surfaces. Fungi infecting ticks were isolated and assumed as entomopathogenic fungi.

In vitro growth profiles of EPF were carried out in Potato Dextrose Agar medium incubated at $29 \mathrm{oC}$ and $75 \%$ relative humidity. Aerial mycelium and mycelium structures were recorded by observing the colony growth and growth pattern. The colony diameter of EPF was measured using scale $(\mathrm{cm})$ on $10^{\text {th }}$ day of full colony growth. The fungal isolates were identified on the basis of colony morphology including colony colour, reverse colony colour, texture, shape and spore structure by using relevant literature (Barnet and Hunter, 1972; Nagamani et al., 2006).

A small unit of surface colony growth of fungus was picked up using sterilized dissecting needle, suspended in distilled water and were uniformly mixed using vortex shaker. One drop of fungal sample was taken on glass slide to which one drop of lacto phenol cotton blue stain was added and the cover slip was applied. The slides were then examined under stereo -binocular microscope and compound microscope for study of morphological characters. The morphological identification of fungi based on size of fungal hyphae and spores was carried out using the ocular and stage micrometry. The isolated fungi from naturally infected ticks were processed for macroscopic and microscopic characteristics using morphological keys (Samson et al., 1988). The species identification of fungal isolates was carried out based on colony growth pattern, macro and microscopic morphological characters. The species confirmation was then again conducted by molecular characterization using RAPD PCR. 


\section{Results and Discussion}

The EPF isolated from soil samples were recorded as Fusarium sp. strain FW24. Rhizopus oryzae, Aspergillus amstelodami and Metarhizium majus. EPF isolated from naturally infected ticks were confirmed as Fusarium beomiforme and Trichoderma harzianum.

\section{Fusarium sp. strain FW24}

The cultural appearances of Fusarium sp. strain FW24 isolates were observed as cottony mycelium with cottony white colony colour whereas the reverse colony colour was observed as light yellow to peach violet. The aerial mycelia were luxuriant and suppressed with fluffy and raised texture. Macroconidia of Fusarium sp. strain FW24 in the present study were found to be oval, septate, slightly curved and thickened with a slightly hook apical cell and foot-shaped basal cell. The average length and width of microconidia was measured as $9.0 \mu \mathrm{m}$ and $3.4 \mu \mathrm{m}$ respectively. The average length of hyphae was recorded as $260 \mu \mathrm{m}$. The length and width of macroconidia ranged from $37.0 \mu \mathrm{m}$ and 3.3 $\mu \mathrm{m}$, respectively. The hyphae length was recorded as 260 to $280 \mu \mathrm{m}$.

Lazarotto et al., (2014) and Maina et al., (2017), observed luxuriant, moderately luxuriant and scanty aerial mycelial growth of Fusarium oxysporum isolates in their studies. The reverse colony colour of the isolates on PDA medium varied from white, pink to purple. The length $\mathrm{X}$ breadth of the microconidia was reported as 46.25 (43.049.5) $X 3.26$ (3.05-3.4) and the length of hyphae as 200 to 300 micron. Gupta et al., (2010) observed the sickle shaped conidia of Fusarium spp. The size of Macroconidia of Fusarium spp. ranges between $28 \times 3.8 \mu \mathrm{m}$ to $42 \times 4.2 \mu \mathrm{m}$ with a mean of $37 \times 3.3 \mu \mathrm{m}$ whereas the length $X$ breadth of the microconidia were ranged from $8 \times 3.0 \mu \mathrm{m}$ to $10 \times 3.4 \mu \mathrm{m}$ with a mean size of $9 \times 3.4 \mu \mathrm{m}$. The number of septae present in the conidia were three. Sporangial size differed between strains and within a single specimen.

\section{Rhizopus oryzae}

Rhizopus oryzae isolates showed abundant filamentous mycelium with brownish to blackish grey colony colour whereas the reverse colony colour was observed as reddish brown. The aerial mycelia were luxuriant and suppressed whereas the texture of mycelium was observed as filamentous and raised. Macroconidia of Rhizopus oryzae in the present study were found to be oval, slightly curved and non septate. The length and width of macroconidia was measured as $1500 \mu \mathrm{m}$ and $18 \mu \mathrm{m}$ respectively whereas the length and width of microconidia ranged from 5.3 $\mu \mathrm{m}$ and $4.3 \mu \mathrm{m}$. respectively. The length of hyphae was recorded as 380 to $450 \mu \mathrm{m}$.

According to Jennessen (2008), the colonies of Rhizopus oryzae were dark grayishblackish brown, up to $10 \mathrm{~mm}$ high, sporangiophores were brownish up to $400 \mu \mathrm{m}$ high and $10 \mu \mathrm{m}$ wide. Sporangia were grayish-black, spherical with up to $100 \mu \mathrm{m}$ in diameter. Chlamydospores were spherical with up to $100 \mu \mathrm{m}$ in diameter. The length $\mathrm{x}$ breadth of Rhizopus oryzae was 5.3x $4.3 \mu \mathrm{m}$.

\section{Trichoderma harzianum}

The isolates of Trichoderma harzianum were appeared as green colour with diffused luxuriant and suppressed aerial mycelium. The reverse colony colour was observed as yellowish brown. Macroconidia of Trichoderma harzianum in the present study were found to be globus in shape. The length of macroconidia ranged from $12.0 \mu \mathrm{m}$ and width was $3.5 \mu \mathrm{m}$. The length of microconidia ranged from $3.5 \mu \mathrm{m}$ and width $4.5 \mu \mathrm{m}$.. The 
length of hyphae was recorded as 250 to 280 $\mu \mathrm{m}$.

The morphological studies conducted by Shah et al., (2012), reported the cottony white and light yellowish mycelium of floppy growth and condition in the T. harzianum isolates was predominantly effuse covering the entire surface of the plates. Conidial colour was observed from white to varying shades of green. Conidia of Trichoderma harzianum $(2.8 \times 2.6 \mu \mathrm{m})$ were globose to subglobose with light green colour.

The length of hyphae was recorded from 250 to $280 \mu \mathrm{m}$. Muthu and Sharma (2016), investigated globosed to subglobosed conidia of Trichoderma. The size of macroconidia ranged from 8-15 x 2-3 $\mu \mathrm{m}$ in length $\mathrm{x}$ breadth. Microconidia varied in size of 3.6 $4.5 \times 3.5-4 \mu \mathrm{m}$ in length $\mathrm{x}$ breadth.

\section{Aspergillus amstelodami}

The thick mycelium of Aspergillus amstelodami was observed with yellowish green colony colour and brownish red reverse colony colour. The aerial mycelia were luxuriant, suppressed and folded in nature with thick, fluffy and dense texture.

Macroconidia of Aspergillus amstelodami were found to be oval in shape and septate. The length and width of macroconidia ranged from $60.0 \mu \mathrm{m}$ and $12.0 \mu \mathrm{m}$. respectively whereas microconidia ranged from $3.9 \mu \mathrm{m}$ and $4.2 \mu \mathrm{m}$. in length and width respectively. The average hyphae length was recorded as 200 to $350 \mu \mathrm{m}$.

Colony characterization of Aspergillus amstelodami reported by Gautam and Bhadauria (2012), showed surface colony colour as dark green with prominent entire margins, reverse colony colour or pigmentation was brownish red, umbonate elevation and very slow colony growth. The conidia were cylindrical with round ends, color ranges from light green to dark green with simple and branched conidiophores. The septate branched hyphae of Aspergillus with length of 200 to $350 \mu \mathrm{m}$, diameter of 7 to 10 $\mu \mathrm{m}$ and globosed vesicle. Fernandes et al., 2012 observed velvety colonies of Aspergillus amstelodami, after incubation at $28 \pm 1 \mathrm{C}$ for 20 days.

The colony colour were predominantly dark green, light green, white or brownish. The colonies of most isolates presented a white edge of variable thickness. The reverses colony colour of colonies was yellow to brownish or orange.

\section{Metarhizium majus}

Metarhizium majus isolates were observed with olive green colony colour whereas the reverse colony colour was observed as yellowish brown..The colonies in the beginning were observed as thick whitish in colour with green border which were turned in olive green after maturation.

The aerial mycelia were luxuriant and suppressed with diffused, fluffy and powdery texture on cultural media. Macroconidia of Metarhizium majus were found to be globus in shape and non septate. The length and width of macroconidia ranged from $12.0 \mu \mathrm{m}$ and 3.5 $\mu \mathrm{m}$ respectively whereas the length and width of microconidia ranged from $5.0 \mu \mathrm{m}$ and 1.90 $\mu \mathrm{m}$ respectively. The length of hyphae was noted as 350 to $400 \mu \mathrm{m}$.

Boucias and Pendland (1998), Bischoff et al., (2009) and Tangthirasunun et al., (2010) recorded conidia size of $M$. anisopliae ranged from 3.9 to $4.2 \mu \mathrm{m}$ with yellowish green heads and diameter 4 to $7 \mu \mathrm{m}$. $M$. anisopliae was divided into two varieties based on size of conidia. 


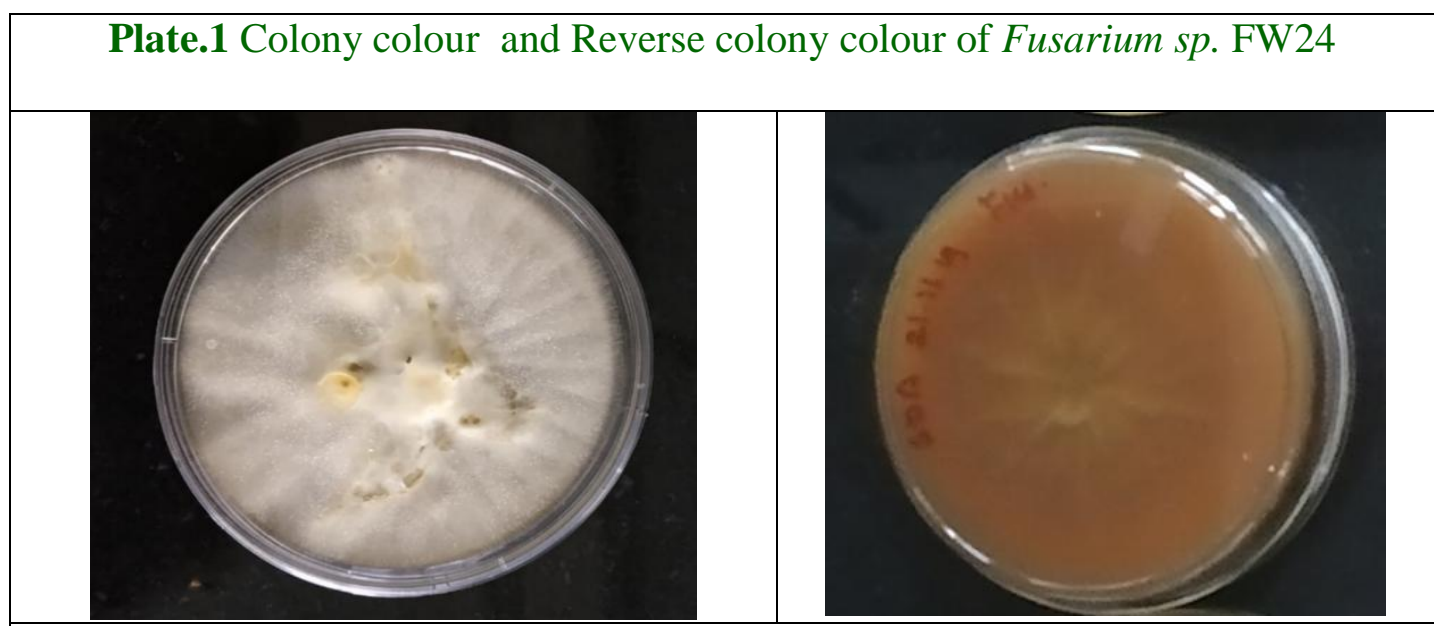

Plate.2 Colony colour and Reverse colony colour of Rhizopus oryzae
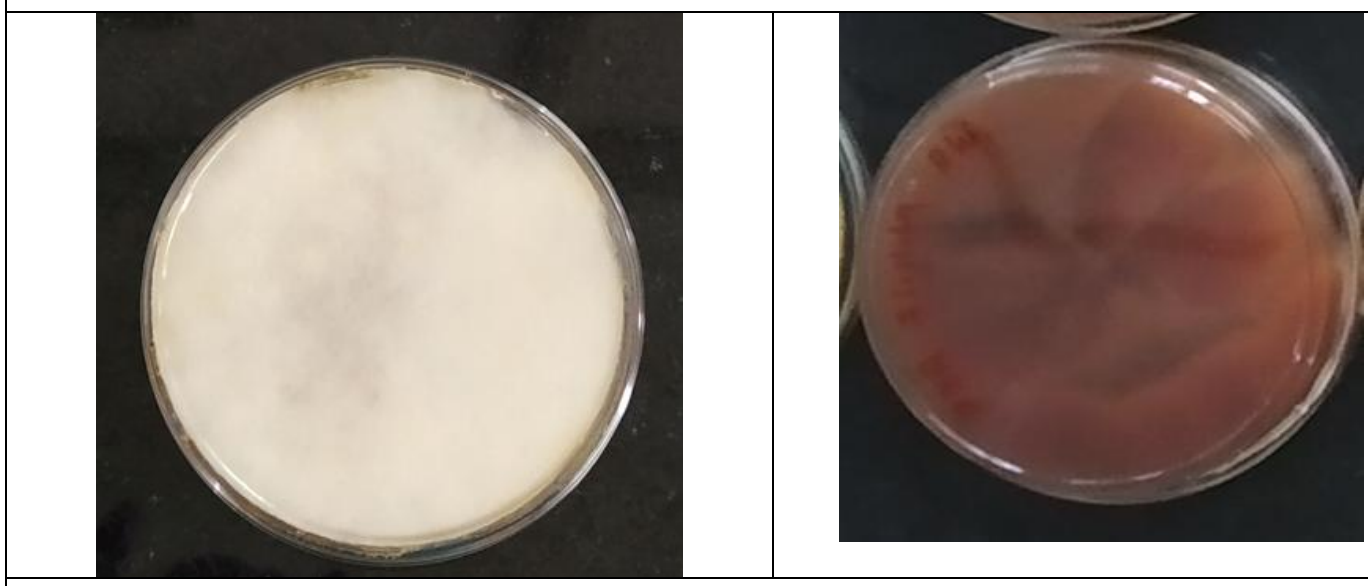

Plate.3 Colony colour and Reverse colony colour of Trichoderma harzianum

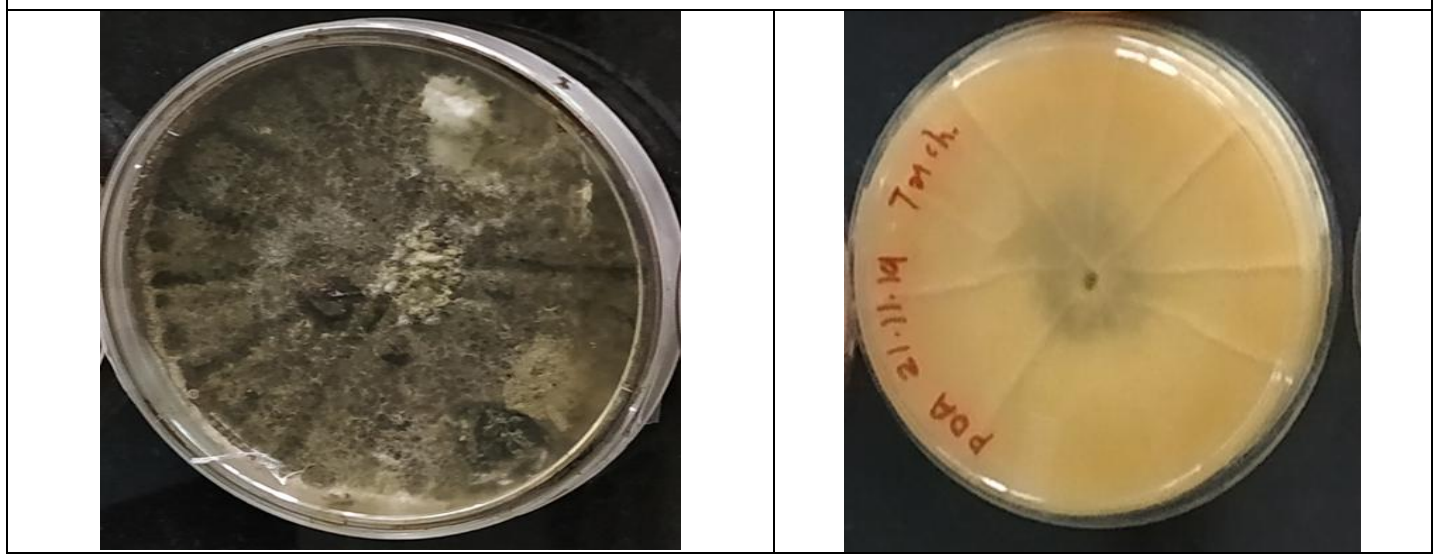




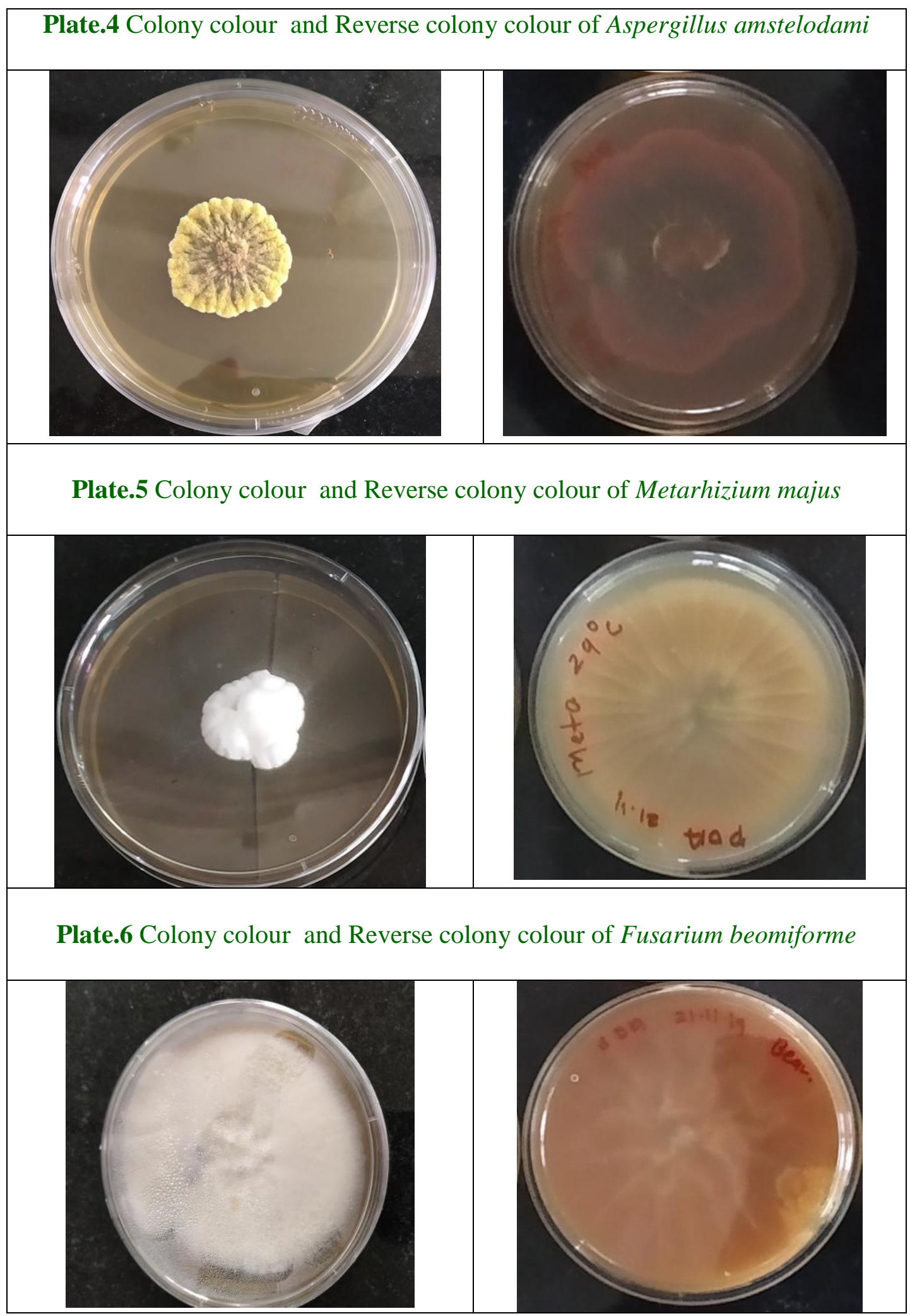




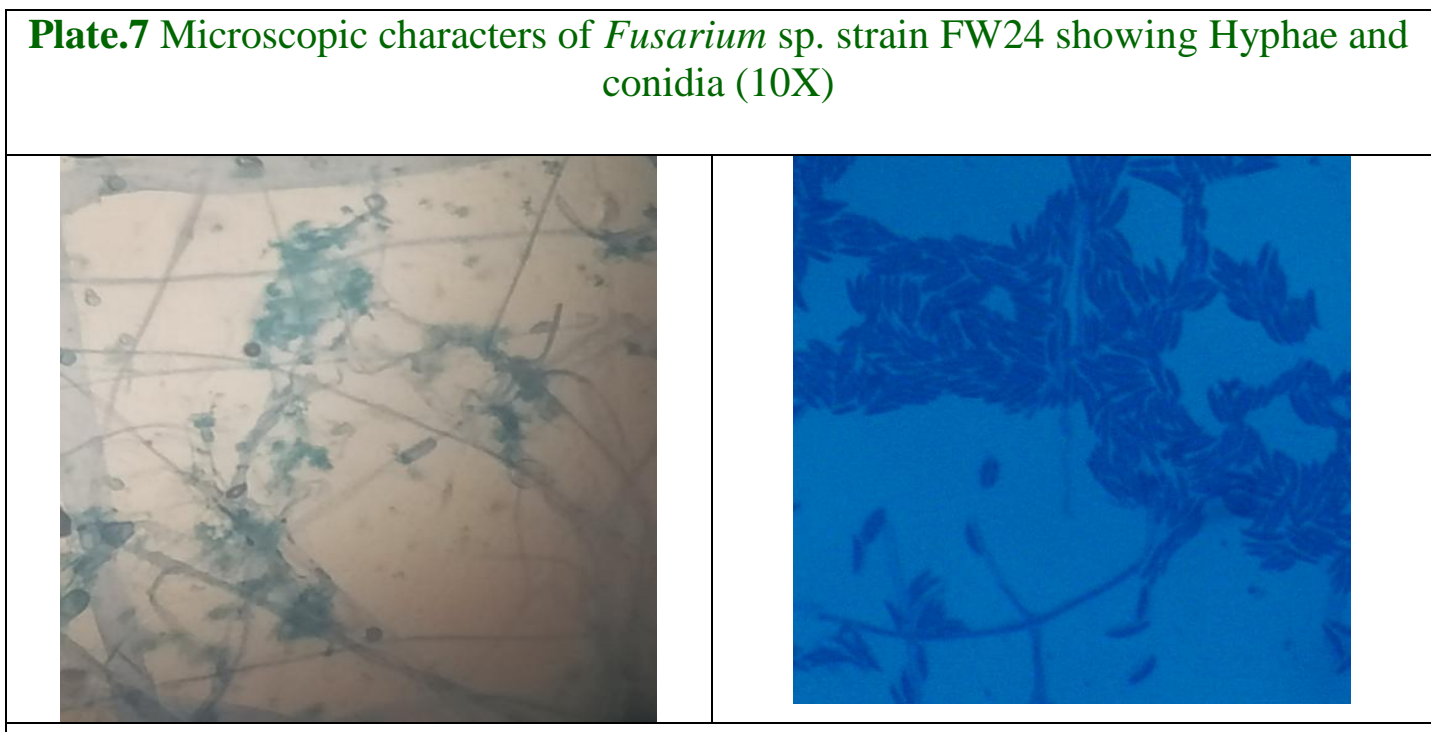

Plate.8 Microscopic characters of Rhizopus oryzae showing Hyphae and conidia $(10 \mathrm{X})$

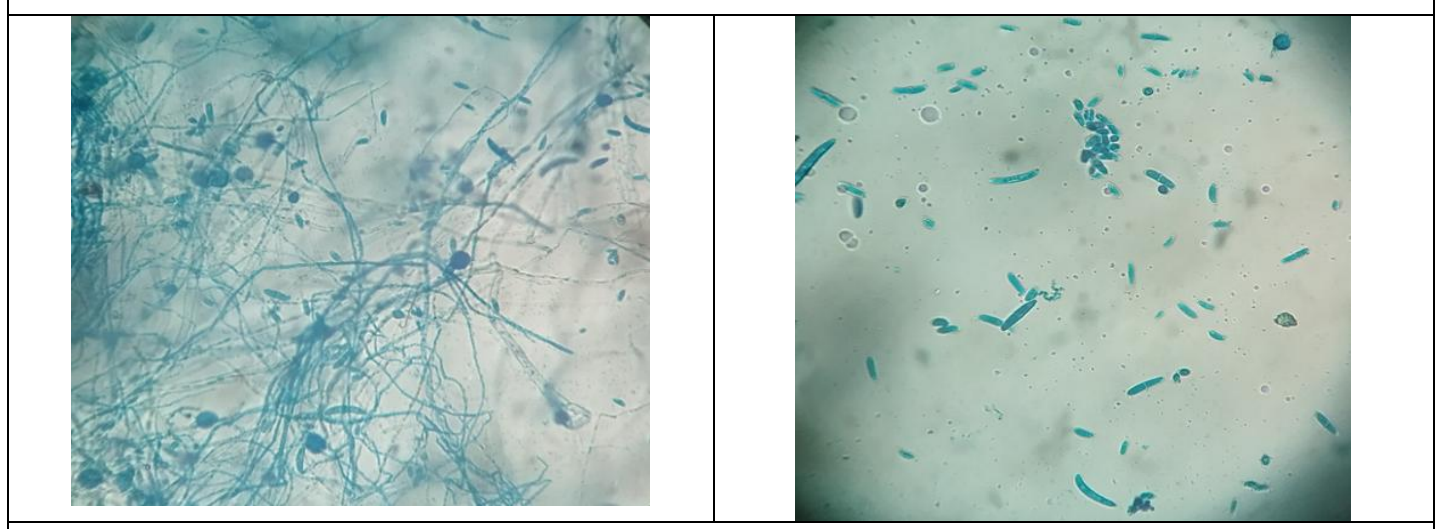

Plate.9 Microscopic characters of Trichoderma harzianum showing Hyphae and conidia (10X)

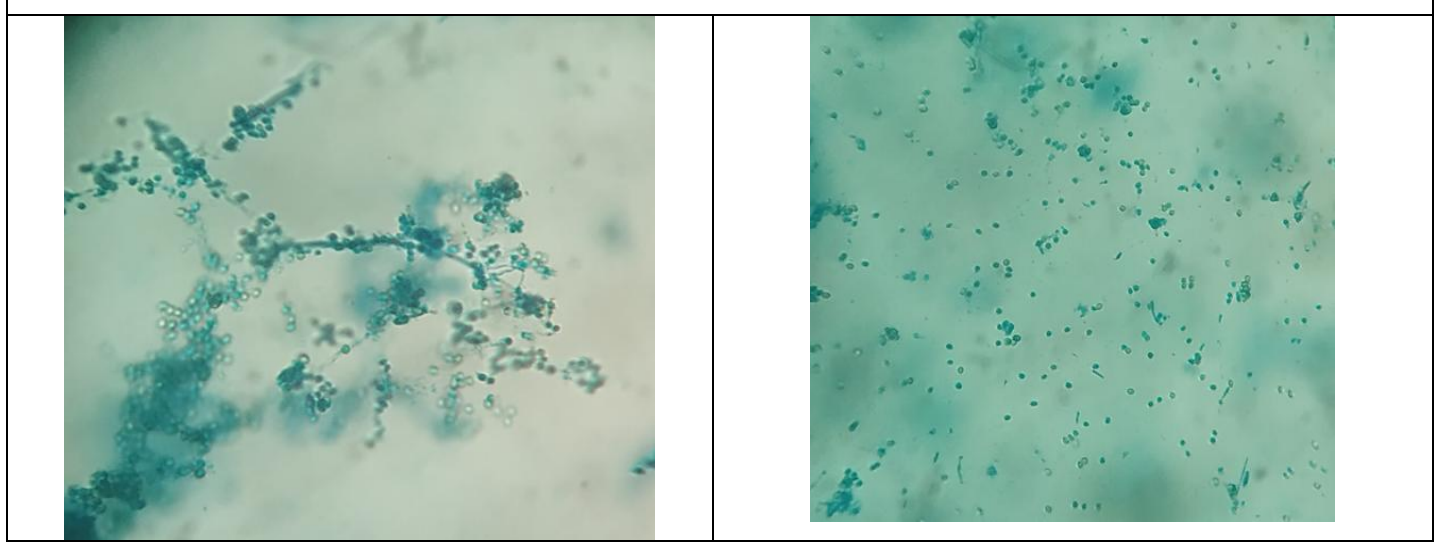




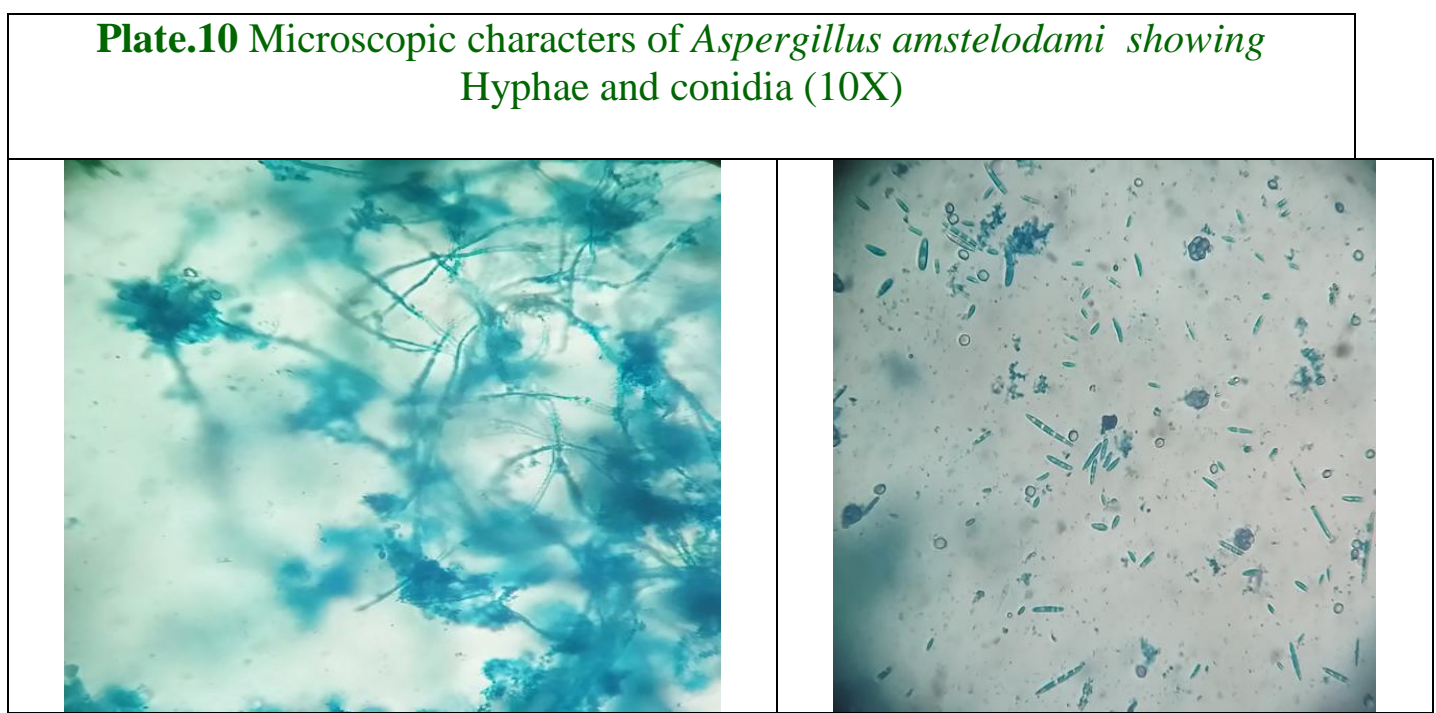

Plate.11 Microscopic characters of Metarhizium majus showing Hyphae and conidia (10X)

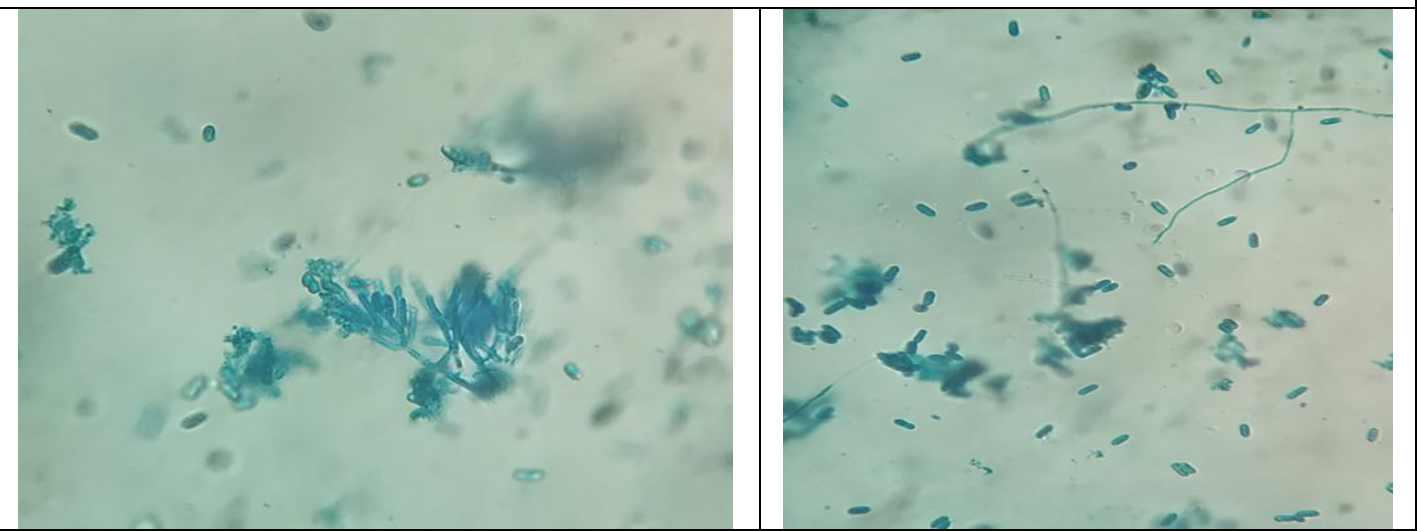

Plate.12 Microscopic characters of Fusarium beomiforme showing Hyphae and conidia (10X)

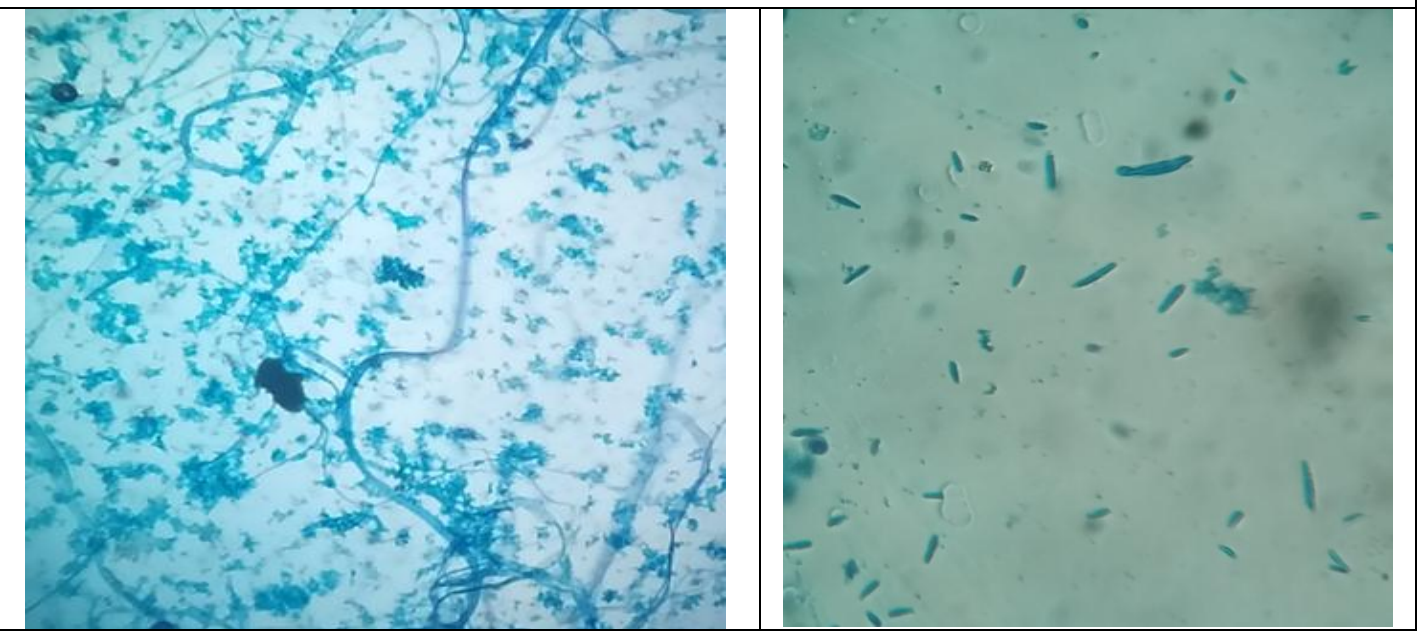


The variety with short conidia was termed as M. anisopliae var. anisopliae whereas the long conidial species are termed as $M$. anisopliae var. majus. The conidia of $M$. anisopliae var. majus are more than $10 \mu \mathrm{m}$ long and are usually $12-13 \mu \mathrm{m}$. In the present study, the long conidial variety of Metarhizium majus was investigated. Length of conidia varied from $4.10 \mu \mathrm{m}$ to $12.59 \mu \mathrm{m}$ whereas width of conidia varied from $1.40 \mu \mathrm{m}$ to $4.75 \mu \mathrm{m}$. The similar range of conidial size was recorded by various workers viz. Riba et al., (1986); Yip et al., (1992); Fernandes et al., (2010) and Sepulveda et al., (2016). The various ranges in macroscopic and microscopic characteristics in various fungal species may be due to species variation, fungal isolates from different climatic zones and cultivation practices.

\section{Fusarium beomiforme}

The cultural appearances of Fusarium beomiforme isolates were observed as abundant, uniform cottony, luxuriant and suppressed mycelium with white colony colour and light yellow reverse colony colour. The texture mycelia were observed as fluffy and raised. Macroconidia of Fusarium beomiforme were found to be oval, slightly curved, thick with a slightly hook apical cell and foot-shaped basal cell. The length and width of macroconidia ranged from $35 \mu \mathrm{m}$ and $3.2 \mu \mathrm{m}$ respectively whereas the length and width of microconidia ranged from $9.0 \mu \mathrm{m}$ and $3.5 \mu \mathrm{m}$ respectively. The number of septa observed was 4 . The length of hyphae was recorded as 350 to $400 \mu \mathrm{m}$.

The colony diameter of Fusarium sp. strain FW24, Rhizopus oryzae, Trichoderma harzianum, Metarhizium majus and Fusarium beomiforme was recorded as $9.0 \mathrm{~cm}$ with uniform growth whereas $4.5 \mathrm{~cm}$ colony diameter of Aspergillus amstelodami with thick folded colony growth was observed on tenth day of culture on Potato Dextrose Agar. The various ranges in macroscopic and microscopic characteristics in various fungal species may be due to species variation, fungal isolates from different climatic zones and cultivation practices.

\section{References}

Barnett, H. L. and Hunter, B. B. 1972. Illustrated genera of imperfect fungi. Third Edition. Minneapolis: Burges Publishing Company

Bischoff, J. F., Rehner, S. A. and Humber, R. A. 2009. A multilocus phylogeny of the Metarhizium anisopliae lineage. Mycologia 101: 512-530.

Boucias, D. G. and Pendland, J. C. 1998. Principles of Insect Pathology. Kluwer academic publisher. Boston.

Fernandes, E. K. K., Keyser, C. A., Chong, J. P., Rangel, D. E. N., Miller, M. P. and Roberts, D.W. 2010. Characterization of Metarhizium species and varieties based on molecular analysis, heat tolerance and cold activity. Journal of Applied Microbiology 108: 115-128.

Gautam, A. K. and Bhadauria, R. 2012.Characterization of Aspergillus species associated with commercially stored triphala powder. African Journal of Biotechnology. 11(104):16814-16823.

Gupta, Vijai Kumar, Misra, Ashok Kumar and Gaur Rajarshi Kumar 2010. Growth Characteristics of Fusarium Spp. Causing Wilt Disease in Psidium Guajava L. In India. Journal of Plant Protection Research. 50 (4); 452-462

Jennessen Jennifer, Rera Johan Schnu, Olssonb Johan, Samsonc Robert A., Dijksterhuisc 2008. Morphological characteristics of sporangiospores of the tempe fungus Rhizopus oligosporus differentiate it from other taxa of the $R$. microsporus group. Mycological research 112:547-563. 
Lazarotto, M., Milanesi, P. M., Muniz, M. F. B., Reiniger, L. R. S., Beltrame, R., Harakava, R. and Blume, E. 2014. Morphological and molecular characterization of Fusarium spp pathogenic to pecan tree in Brazil. Genet. Mol. Res. 13 (4): 9390-9402.

Maina, P. K., Wachira, P. M., Okoth, S. A. and Kimenju, J. W. 2017. Cultural, morphological and pathogenic variability among Fusarium oxysporum $f$. $s p$. phaseoli causing wilt in french bean (Phaseolus vulgaris L.). Journal of Advances in Microbiology

Muthu Kumar A. and Sharma Pratibha. 2016. Morphological characterization of biocontrol isolates of Trichoderma to study the correlation between morphological characters and biocontrol efficacy. International Letters of Natural Sciences. 55: 57-67.

Nagamani, A., Kumar, I. K. and Manoharachary, C. 2006. Hand book of Soil Fungi, I.K. International Publishing House Pvt Ltd, New Delhi, India.

Pell, J. K., Eilenberg, J., Hajek, A. E., Steinkraus, D. C., Butt, T. M., Jackson, C. and Magan, N. 2001. Fungi as biocontrol agents: Progress, Problems and Potential. CAB International, Wallingford. 71 153.

Riba, G., Bouvier-Fourcade, I. and Caudal, A. 1986. Isozyme polymorphism in Metarhizium anisopliae (Deuteromycotina: Hyphomycetes) entomogenous fungi. Mycopathologia. 96:161-169.

Samish, M., Ginsberg, H. and Glazer, I. 2004.
Biological control of ticks. Parasitology, 129: 389-403.

Samson, R. A., Evans, H. C. and Latge, J. P.1988. Atlas of entomopathogenic fungi. Springer-Verlag Berlin, Heidelberg, New York.1-187.

Sepulveda María, Vargas Marisol, Gerding Macarena, Ceballos Ricardo, and Oyarzua Pia. 2016. Molecular, morphological and pathogenic characterization of six strains of Metarhizium spp. (Deuteromycotina: Hyphomycetes) for the control of Aegorhinus superciliosus (Coleoptera: Curculionidae). Chilean J. Agric. Res.76 (1):77-83.

Shah, S., Nasreen, S. and Sheikh, P. A. 2012. Cultural and morphological characterization of Trichoderma spp. associated with green mold disease of Pleurotus spp. In Kashmir. Research Journal of Microbiology, 7: 139-144.

Tangthirasunun, N., Poeaim, S., Soytong, K., Sommartya, P. and Popoonsak, S. 2010. Variation in morphology and ribosomal DNA among isolates of Metarhizium anisopliae from Thailand Journal of Agricultural Technology. 6(2): 317-329

Waksman, S. A. 1922. A method for counting the number of fungi in the soil. J. Bact.; 7 (3):339-341

Yip, H., Rath, A. C. and Koen, T. B. 1992. Characterization of Metarhizium anisopliae isolates from Tasmanian pasture soils and their pathogenicity to redheaded cockchafer (Coleoptera: Scarabaeidae: Adoryphorus couloni). Mycological Research 96: 92-96.

\section{How to cite this article:}

Jumade Pratibha, S. Pal and Sanyal, P. K. 2021. Morphological and Colony Characterization of Durg Isolates of Entomopathogenic Fungi as a Biocontrol Agent against Tick infestation in Cattle. Int.J.Curr.Microbiol.App.Sci. 10(07): 327-336.

doi: https://doi.org/10.20546/ijcmas.2021.1007.035 